National Marine

Fisheries Service

NOAA
Fishery Bulletin

ar established in 1881 \%
Spencer F. Baird

First U.S. Commissioner of Fisheries and founder of Fishery Bulletin

\begin{abstract}
A hierarchical Bayesian approach was used to model the spatiotemporal habitat distribution of spiny dogfish (Squalus acanthias) of both sexes (adults) caught during trawl surveys conducted by the Northeast Area Monitoring and Assessment Program in inshore coastal waters between New England and North Carolina during 2007-2013. The best model for predicting catch per unit of effort (CPUE) for this species includes the following relevant variables: bathymetry, sea surface temperature, salinity, chlorophyll- $a$ (chl- $a$ ) concentration, season and time of survey, and a random spatial effect for both sexes. Predicted CPUE was related to depth for both sexes; females occurred in shallower waters than those in which males occurred. Also, more females than males were predicted to occur in warmer, less saline and more productive (higher chl- $a$ concentration) waters. Seasonality and time of predicted CPUE indicated that the abundance of females was higher in inshore coastal waters in the spring and in the morning, and the abundance of males was greater in the afternoon and in the fall in the same area. Collectively, these results provide information that enhances our understanding of differences in habitat selection and spatiotemporal distribution of the 2 sexes of this species-information that can help to modify present management strategies for the U.S. Atlantic fishery.
\end{abstract}

Manuscript submitted 15 April 2016. Manuscript accepted 17 November 2016. Fish. Bull. 115:89-100 (2017).

Online publication date: 6 December 2016. doi:10.7755/FB.115.1.8

The views and opinions expressed or implied in this article are those of the author (or authors) and do not necessarily reflect the position of the National Marine Fisheries Service, NOAA.

\title{
Modeling the habitat distribution of spiny dogfish (Squalus acanthias), by sex, in coastal waters of the northeastern United States
}

\author{
Andrea Dell'Apa (contact author) ${ }^{1}$ \\ Maria Grazia Pennino² \\ Christopher Bonzek ${ }^{3}$ \\ Email address for contact author: dellapa.andrea@gmail.com \\ ${ }^{1}$ Earth Resources Technology Inc. \\ 1315 East-West Highway \\ Silver Spring, Maryland 20910 \\ 2 Universidade Federal do Rio Grande do Norte (UFRN) \\ Department of Ecology \\ Campus Universitário s/n, Lagoa Nova \\ CEP 59.098-970 Natal (RN), Brazil \\ ${ }^{3}$ Virginia Institute of Marine Science \\ College of William and Mary \\ P.O. Box 1346 \\ Gloucester Point, Virginia 23062-1346
}

The spiny dogfish (Squalus acanthias) is a small shark commonly found in oceanic and coastal temperate waters throughout the world, at depths less than $900 \mathrm{~m}$ (Compagno et al., 2005; Dell'Apa et al., 2015). The species is sexually dimorphic; adult females, on average, are larger than adult males (Nammack et al., 1985). Moreover, aggregations of adult individuals are segregated by sex and size (Ford, 1921; Shepherd et al., 2002; Dell'Apa et al., 2014)-a common occurrence with elasmobranchs (Springer, 1967; Sims, 2005). Sexual segregation can be the effect of social segregation, in which the interaction between the sexes is limited by behavioral differences between the sexes, or it can be the effect of habitat segregation, in which the 2 sexes use habitats with different physical and environmental characteristics. Social segregation and habitat segregation can also occur simultaneously for the two sexes and can lead to differences in spatial distribution and habitat associations between the sexes (Wearmouth and Sims, 2008). Additionally, sexual dimorphism may influence feeding habits in live-bearing elasmobranchs (Sims, 2005), resulting in the 2 sexes having evolved specific physiological requirements that have led to differences in diet and prey preferences (Ruckstuhl and Clutton-Brock, 2005). Consequently, the 2 sexes may occupy different habitats characterized by different prey compositions and thus reduce intraspecific competition (Sims, 2005).

For commercially important species, such as the spiny dogfish (Lack, 2006; Dell'Apa et al., 2013), predicting abundance and identifying habitat associations in response to environmental and spatiotemporal factors can be a valuable approach to the development of sustainable fishery strategies (Perry and Smith, 1994; Pittman et al., 2011; Espinoza et al., 2014). For assessments of many elasmobranchs, understanding habitat associations is complex and 
confounded by sexual segregation that can lead to spatial or temporal segregation (Conradt, 2005).

On the northwest Atlantic continental shelf, habitat use and seasonal movements of spiny dogfish have been reported to differ by sex-the key driver being seasonal changes in temperatures (Shepherd et al., 2002; Methratta and Link, 2007; Sagarese et al., 2014a, 2014b). Additionally, it has been suggested that the movement of species is influenced by the distribution of their prey (Overholtz and Tyler, 1985; Sagarese et al., 2014b). In this region, aggregations of mature females are commonly found inshore, in shallower and warmer waters, and aggregations of mature males dominate offshore, deeper and colder waters (Shepherd et al., 2002; Sagarese et al., 2014a). Collectively, the spiny dogfish is characterized by north-south seasonal migrations: fish overwinter off North Carolina and migrate northward during the spring to waters in New England and Gulf of Maine, where they remain between summer and late fall before their southward migration (Rulifson, 2010).

A regional study in which fishery-dependent data were used and that was conducted in inshore coastal waters inside and off the peninsula of Cape Cod, Massachusetts (Dell'Apa et al., 2014), elucidated the local habitat association of spiny dogfish, by sex, and provided information on the potential drivers of sexual segregation in this species. The results of that study indicated that the distribution of the 2 sexes differed by location, season, and time. The highest occurrence of adult males was found early in the day and between spring and early autumn in inshore waters off the eastern side of the sampling area in relatively close proximity to deep water $(>100 \mathrm{~m})$, and highest occurrence of adult females was found inshore, in waters (depths $<78$ $\mathrm{m})$ shallower than the waters in which adult males occurred, and farther inside the Cape Cod peninsula than the other locations surveyed (Dell'Apa et al., 2014). Dell'Apa et al. (2014) suggested that adult females may actively seek shallow waters as a strategy to elude adult males and energy-demanding copulation-a tactic that results in spatial segregation. Alternatively, in deeper coastal areas, where males are usually more abundant, adult females may synchronize their different habitatselection behavior with that of adult males, resulting in temporal segregation (Dell'Apa et al., 2014).

Overall, the results of that study indicate that sexual segregation in spiny dogfish, in the Cape Cod area, occurs both spatially and temporally and is strongly influenced by depth. Different behavioral choices by each of the sexes are reflected in their preferred habitat associations and indicate that depth and time, but likely not temperature, are potential key drivers for sexual segregation in spiny dogfish (Dell'Apa et al., 2014). However, that study was based on limited data collected through fishery-dependent surveys in a regionally restricted inshore coastal area, and the findings may not be representative of the entire U.S. Atlantic stock of spiny dogfish. Therefore, for fishery management purposes it would be useful to analyze existing data sets from a larger coastal area, one that encompasses the entire range of the current commercial fishery between New England and North Carolina.

In addition, it would be beneficial to analyze comparable regional data from fishery-independent inshore surveys. In this regard, the nearshore trawl surveys conducted by the Northeast Area Monitoring and Assessment Program (NEAMAP) in the mid-Atlantic represent the most suitable data source that is available for completing a more extensive study on the influence of environmental habitat characteristics, season, and time of day on the distribution of spiny dogfish in inshore coastal waters of the northeastern United States.

The aim of this study was to use the NEAMAP survey data to model the abundance of spiny dogfish, by sex, in inshore coastal waters of the U.S. Atlantic, by considering oceanographic (i.e., sea-surface temperature [SST], salinity, and chlorophyll-a [chl- $a$ ] concentration), topographic (i.e., depth, slope, and distance to land), and temporal (i.e., season and time of day) characteristics as predictive variables for catch per unit of effort (CPUE). This study involved the use of hierarchical Bayesian spatiotemporal models and is the first one to use a large fishery-independent database as a source of data for analysis and prediction of the habitat distribution of spiny dogfish along the northwest Atlantic inshore coastal area, by sex and by time of day. The results of this study provide information on the spatial and temporal distribution of adult spiny dogfish that will be valuable for fishery managers because it will enable the adoption of enhanced management strategies for the fishery for spiny dogfish in the U.S. Atlantic that are based on the sexual segregation exhibited by this species.

\section{Materials and methods}

\section{Mid-Atlantic surveys}

NEAMAP surveys are conducted in the coastal waters bounded by the western edge of Cape Cod, Massachusetts, and by Cape Hatteras, North Carolina. From Montauk, New York, and southward, sampling is confined within the 18.3-m depth contour. In the deeper nearshore waters off southern New England, the deepest stations extend to about $36.6 \mathrm{~m}$ (Fig. 1). NEAMAP conducts 2 cruises per year, one each in spring (AprilMay) and fall (September-October), timed to roughly coincide with offshore surveys carried out by the NOAA Northeast Fisheries Science Center (NEFSC). Each NEAMAP cruise samples 150 stations distributed among 17 regions and 2 depth strata. To allow comparisons with current NEFSC surveys, NEAMAP adopted the bottom trawl design developed for the NEFSC by the Northeast Trawl Survey Advisory Panel, joint board of the Mid-Atlantic and New England Fishery Management Councils. The NEAMAP conducts surveys by fishing with a 3-bridle, 4-seam bottom trawl with a net of 400 meshes (of $12 \mathrm{~cm}$ width) for a total length of 48 


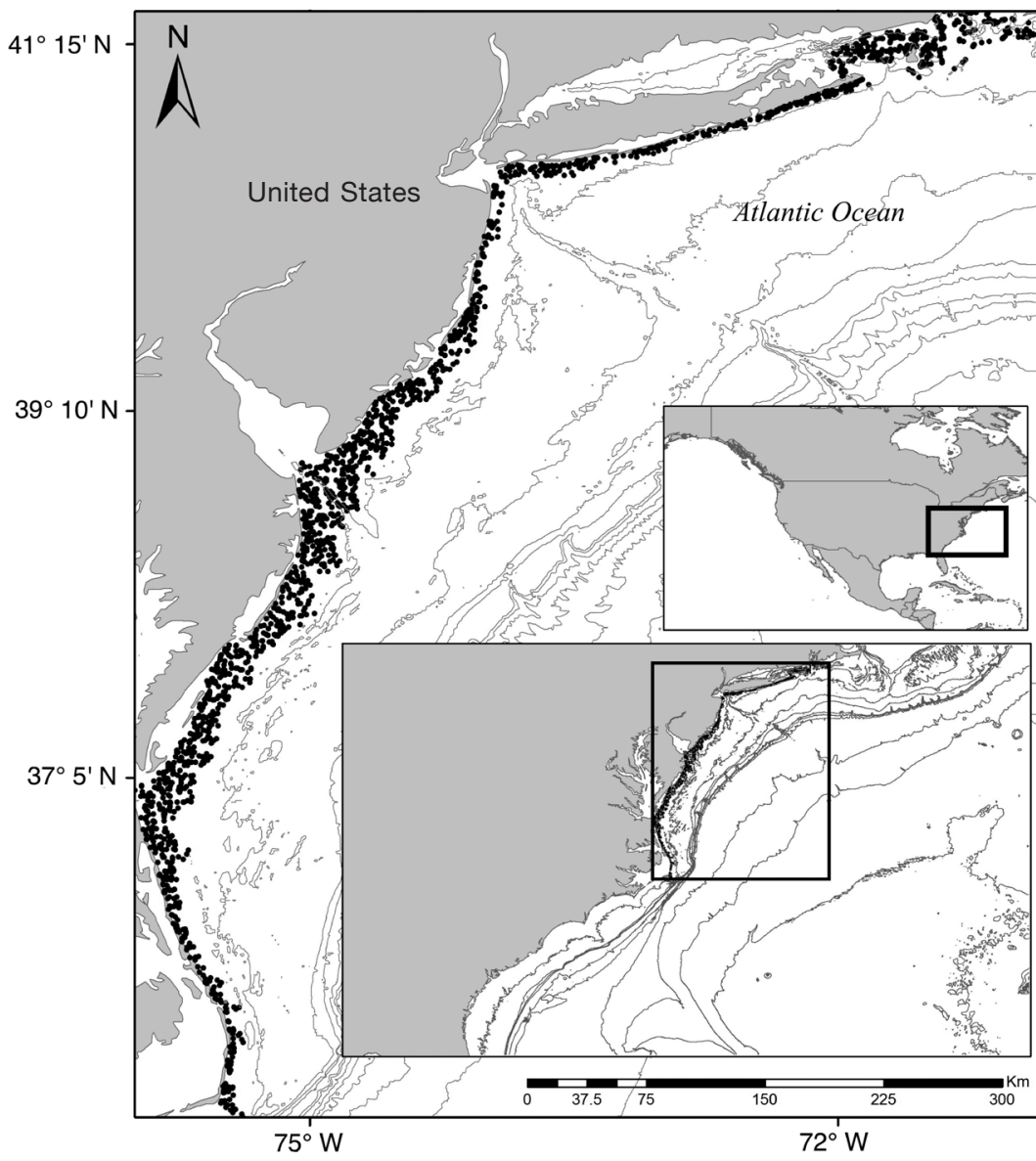

Figure 1

Map of the study area. Black circles represent the locations of 1820 trawl hauls conducted in inshore coastal waters of the mid-Atlantic during surveys by the Northeast Area Monitoring and Assessment Program. Data from these surveys were used to determine the distribution of spiny dogfish (Squalus acanthias) between New England and North Carolina in 2007-2013.

$\mathrm{m}$, a $7.6-\mathrm{cm}$ cookie sweep, and a $2.5-\mathrm{cm}$ knotless liner in the codend. The doors are 1.7-m Thyboron Type IV.

\section{Data collection, sources, and analysis}

Fishery-independent data on spiny dogfish were collected during the NEAMAP surveys in spring and fall of 2007-2013 on the F/V Darana $R$. As described by Bonzek et al. ${ }^{1}$, for each haul, up to approximately 18 spiny dogfish were examined to determine individual length (precaudal length [PCL] in centimeters), weight, sex, and maturity (males only, by external examination of the claspers). All other specimens were weighed in total and measured individually. In rare cases of very

\footnotetext{
${ }^{1}$ Bonzek, C. F., J. Gartland, R. A. Johnson, and J. D. Lange Jr. 2008. NEAMAP Near Shore Trawl Survey: peer review documentation. A report to the Atlantic States Marine Fisheries Commission by the Virginia Institute of Marine Science (VIMS), Gloucester Point, VA. [Available from VIMS, P.O. Box 1346, Gloucester Point, VA 23062-1346].
}

large catches, those individuals not processed as described were counted (or weighed) in full without further processing, before being released. When subsampling occurred, the attributes of the subsampled portion (e.g., sex ratios and lengths) were expanded to the total catch (Bonzek et al. ${ }^{1}$ ). Additionally, for each haul, the date, starting and ending times, and location (latitude and longitude) were recorded.

For the purpose of our analysis, the CPUE for spiny dogfish, by sex, for each trawl haul was calculated as the total number of individuals of each sex for each 20 min of trawling. The length of individuals was converted from PCL to total length (TL) in centimeters by using the conversion factor $(T L=P C L / 0.807)$ available for this species in FishBase (website). The analysis for this study included only adult females $(>80 \mathrm{~cm}$ TL) and adult males ( $>60 \mathrm{~cm} \mathrm{TL})$, on the basis of the size at maturity reported for this species in the northwest Atlantic (Nammack et al., 1985). It is worth noting that at the time of the study by Nammack et al.'s (1985), 
the stock of spiny dogfish was not subjected to the intense exploitation by the domestic commercial fishery that began in the early 1990s. This exploitation caused this stock to be declared overfished in 1998 and resulted in the development of a fishery management plan in 1999 for this species in federal waters $(5-322 \mathrm{~km}$ offshore) by the New England and Mid-Atlantic Fishery Management Councils (MAFMC ${ }^{2}$ ). The federal plan was further reinforced by an interstate fishery management plan for state waters (0-5 km offshore) developed by the Atlantic States Marine Fisheries Commission in 2002 (ASMFC 3 ; Dell'Apa et al., 2015).

Additionally, the commercial fishery has preferentially targeted adult females because of their larger size. This fishing strategy has resulted in a recent increase in the adult male:female sex ratio in the catch of this species and in a decrease in the average size at maturity for adult females in the U.S. Atlantic stock from the sizes reported by Nammack et al. (1985) (Sosebee, 2005; Rago and Sosebee ${ }^{4}$-a drop from $80 \mathrm{~cm} \mathrm{TL}$ to about $74.5 \mathrm{~cm}$ TL, according to Bubley et al. (2013). Overall, this decline indicates that the actual size at maturity of adult females from the NEAMAP surveys during 2007-2013 was likely to have been smaller than the $80 \mathrm{~cm}$ TL used in our analysis. However, because no interannual variability in the predicted CPUE of adult females was found by using the $80-\mathrm{cm}$-TL size at maturity criterion and because of the inherent difficulties in choosing an alternative size criterion as a result of consistent fluctuation in the annual average size at maturity reported for adult females (Marques da Silva and $\operatorname{Ross}^{5}$ ), we opted to adopt a more conservative approach by using the most commonly accepted size at maturity reported by Nammack et al. (1985).

For statistical purposes, the time of each set was classified into 3 categories: morning (between 6:00 AM and 12:59 PM), afternoon (between 1:00 PM and 6:59 $\mathrm{PM}$ ), and night (between 7:00 PM and 5:59 AM), according to the time partitioning used by Dell'Apa et al. (2014).

Six environmental variables were included in the analysis: bathymetry (mean depth of each haul in feet and converted to meters for analysis), distance to shore (measured in meters), slope of the seabed (percent grade), monthly mean SST (measured in degrees Cel-

\footnotetext{
2 MAFMC (Mid-Atlantic Fishery Management Council). 1999. Spiny dogfish fishery management plan, 292 p. MidAtlantic Fishery Management Council, Dover, DE. [Available from website.]

3 ASMFC (Atlantic States Marine Fisheries Commission). 2002. Interstate fishery management plan for spiny dogfish. ASMFC, Fish. Manage. Rep. 40, 98 p. [Available from website.]

${ }^{4}$ Rago, P., and K. Sosebee. 2012. Update on the status of spiny dogfish in 2012 and initial evaluation of harvest at the Fmsy proxy, 43 p. Science and Statistical Committee, Mid-Atlantic Fishery Management Council, Dover, DE.

${ }^{5}$ Marques da Silva, H., and M. R. Ross. 1993. Reproductive strategies of spiny dogfish, Squalus acanthias, in the NW Atlantic. ICES Council Meeting (C.M.) Documents 1993/ G:51,18 p. [Available from website.]
}

sius), monthly mean chl- $a$ concentration (measured in milligrams per cubic meter), and monthly mean values of practical salinity.

Data for 3 variables-SST, chl- $a$ concentration, and salinity-were extracted from the NASA Earth Observations website (website) as long-term monthly mean climate data. Bathymetry was derived from the same NASA Earth Observations website by using the General Bathymetric Chart of the Oceans (GEBCO) grid (website). In addition, data for bathymetry were collected at each haul location. These data were used to correct and check the information on final mean depth. When a discrepancy occurred between the GEBCO and survey data, a mean of the values in the 2 data sets was used.

Distances to the coast and slope gradients were derived from the bathymetry map created with the GEBCO grid, by using the Near (World Equidistant Cylindrical coordinate system) and Slope Spatial Analyst tools in ArcGis 9.26 (Esri, Redlands, CA).

All the covariates were aggregated at a resolution of $0.25^{\circ} \times 0.25^{\circ}$ and were transformed into raster layers with the raster package (Hijmans, 2013) in R, vers. 3.1.2 ( $\mathrm{R}$ Core Team, 2014). To check collinearity between explanatory environmental variables, a draftsman's plot and the Pearson's correlation index were used. Because variables were not correlated highly with coefficients of correlation $(r)<0.5$, they were considered in further analyses.

\section{Modeling species abundance}

For the purpose of our analysis and modeling, we used the spatial distribution approach, which combines observations of species occurrence or abundance with environmental estimates to predict spiny dogfish distribution at locations that were not sampled (Austin, 2007; Elith and Leathwick, 2009). Different approaches and methods can be used to model the spatial distribution of a species. However, most of the common applications do not always provide accurate results when run with traditional prediction methods (i.e., frequentist inference), often because of a large amount of spatiotemporal variability in the data that characterizes dynamic marine ecosystems (Roos et al., 2015). To account for this variability, we used hierarchical Bayesian spatiotemporal models in our study.

Bayesian approaches have several advantages over traditional methods and have been applied successfully to fisheries studies (Colloca et al., 2009; Muñoz et al., 2013; Pennino et al., 2014). Bayesian methods allow the inclusion of both the observed data and model parameters as random variables (Banerjee et al., 2004) and provide more realistic and accurate estimations of uncertainty (Pennino et al., 2014). Additionally, they allow the use of spatial and temporal components as a

\footnotetext{
${ }^{6}$ Mention of trade names or commercial companies is for identification purposes only and does not imply endorsement by the National Marine Fisheries Service, NOAA.
} 


\section{Table 1}

Summary of variables as potential fixed effects that influence the distribution of spiny dogfish (Squalus acanthias) in the mid-Atlantic and included in Bayesian models. SST=sea-surface temperature; chl$a=$ chlorophyll- $a$ concentration; practical salinity is a ratio and does not have physical units.

\begin{tabular}{llc}
\hline Variable & \multicolumn{1}{c}{ Description } & Units \\
\hline Bathymetry & Mean fishing depth of haul & $\mathrm{m}$ \\
Slope & Seabed slope at the sampling station & $\%$ grade \\
Distance to shore & Distance from the coast at the sampling station & $\mathrm{m}$ \\
SST & SST monthly value of haul & ${ }^{\circ} \mathrm{C}$ \\
Chl- $a$ & Chl- $a$ monthly value of haul & $\mathrm{mg}^{3} \mathrm{~m}^{3}$ \\
Salinity & Salinity of the water & - \\
Season & Season when haul was sampled & Spring, fall \\
Time & Time when haul was sampled & Morning, afternoon, night
\end{tabular}

random-effect term, reducing their influence on the estimation of the habitat variables (Gelfand et al., 2006).

Hierarchical Bayesian spatiotemporal models were used to predict abundance of spiny dogfish, by sex, with respect to explanatory variables, as well as to describe the main spatial distribution changes over time, by sex. These models are extremely applicable to studies characterized by data observed at continuous locations within a defined spatial area, as was the case for the data set used in this study. Values of CPUE from the NEAMAP surveys were considered appropriate proxies for levels of abundance of spiny dogfish.

The spatial variation of the CPUE values for spiny dogfish, by sex, was modeled by using a hierarchical Bayesian spatiotemporal approach, specifically a Poisson point process model with log-linear intensity. It was assumed that the number of spiny dogfish at each station sampled, $Y_{\mathrm{i}}$, has a Poisson distribution with rate $t_{\mathrm{i}} \lambda_{\mathrm{i}}$, where $t_{\mathrm{i}}$ is the observation time at site $i$ and $\lambda_{\mathrm{i}}$ is proportional to relative species abundance at station $i$ and measures the survey expectation for a unit observation time, according to this general formulation:

$$
\log \left(\lambda_{\mathrm{i}}\right) i=\alpha+X_{\mathrm{ij}} \beta+Y_{\mathrm{j}}+W_{\mathrm{i}}
$$

where $\alpha=$ the intercept;

$X_{\mathrm{ij}}=$ the matrix of covariates at the year $j$ and the station $I$;

$\beta=$ the vector of the regression coefficients;

$Y_{\mathrm{j}}=$ the component of the temporal unstructured random effect at the year $j$; and

$W_{\mathrm{i}}=$ the spatially structured random effect at the station $i$.

In this model, independence between the sampling locations is assumed. However, some spatial autocorrelation may be present in the data set because the abundance of a species at nearby stations is influenced by similar environmental parameters. Consequently, adjacent, or nearby, stations would be expected to be similar in terms of abundance of spiny dogfish. The $W_{\mathrm{i}}$ accounts for this influence. For each of the models for both sexes, 8 potential fixed-effects were considered: 6 environmental variables and 2 temporal variables (Table 1).

For all the parameters considered in the fixed-effects model, a vague zero-mean Gaussian prior distribution with a variance of 100 was assigned, and a zero-mean Gaussian prior distribution with a Matern covariance structure was assumed for the spatial effect (for more details about the spatial component, see Muñoz et al., 2013). Finally, for the temporal effect, a LogGamma prior distribution with the parameters of shape and scale equal to 1 and $5 \times 10^{5}$, respectively, was assumed for the $\log$-precision parameter $\lambda_{\mathrm{j}}$, and $j$ represented the year.

For each parameter, a posterior distribution was obtained. Unlike the mean and confidence interval produced by classical analyses, this type of distribution enables explicit probability statements about the parameter. Therefore, the region bounded by the 0.025 and 0.975 quantiles of the posterior distribution results in an intuitive interpretation: for a specific model, the unknown parameter is $95 \%$ likely to fall within this range of values $(95 \%$ credibility interval $[\mathrm{CrI}])$.

All models obtained by combining environmental, spatial, and temporal variables and the possible interactions were fitted and compared by using the measures of the deviance information criterion (DIC) (Spiegelhalter et al., 2002) and the cross-validated logarithmic score (LCPO) (Roos and Held, 2011). Specifically, smaller DIC and LCPO values indicate better fit and predictive quality.

All the analyses were performed with the integrated nested laplace approximation (INLA) method that is implemented in Rue et al., 2009; Martins et al., 2013 and with the R-INLA package (website) in $\mathrm{R}$ software.

\section{Model validation}

Two approaches were used to assess the predictive accuracy of the selected model. First, the predicted and observed values from the full data set were compared. 


\section{Table 2}

Summary of the posterior distributions of the fixed effects for the best model of distribution of spiny dogfish (Squalus acanthias), by sex. This summary contains the mean, standard deviation (SD), median $\left(\mathrm{Q}_{0.5}\right)$, and $95 \%$ credible interval $\left(\mathrm{Q}_{0.025}\right.$ to $\left.\mathrm{Q}_{0.975}\right)$, the latter of which is a central interval containing the $95 \%$ of the probability under the posterior distribution. SST=sea-surface temperature; chl$a=$ chlorophyll- $a$ concentration.

\begin{tabular}{|c|c|c|c|c|c|c|}
\hline Sex & $\begin{array}{l}\text { Predictors of } \\
\text { distribution }\end{array}$ & Mean & SD & $\mathrm{Q}_{0.025}$ & $\mathrm{Q}_{0.5}$ & $\mathrm{Q}_{0.975}$ \\
\hline \multirow[t]{8}{*}{ Females } & Intercept & 0.55 & 0.94 & 0.03 & 0.62 & 1.22 \\
\hline & Bathymetry & -1.14 & 0.05 & -2.52 & -1.05 & -0.22 \\
\hline & SST & 0.35 & 0.03 & 0.08 & 0.30 & 1.98 \\
\hline & Chl- $a$ & 0.25 & 0.02 & 0.04 & 0.19 & 1.05 \\
\hline & Salinity & -0.94 & 0.04 & -1.65 & -0.92 & -0.11 \\
\hline & Season (spring) & 1.45 & 0.05 & 0.34 & 1.35 & 2.06 \\
\hline & Time (night) & -0.65 & 0.03 & -1.24 & -0.57 & -0.12 \\
\hline & Time (morning) & 0.88 & 0.03 & 0.32 & 0.67 & 1.43 \\
\hline \multirow[t]{8}{*}{ Males } & Intercept & 0.88 & 0.12 & 0.24 & 0.86 & 1.87 \\
\hline & Bathymetry & 1.85 & 0.05 & 1.44 & 1.83 & 2.36 \\
\hline & SST & -1.02 & 0.08 & -2.33 & -0.98 & -1.51 \\
\hline & Chl- $a$ & -0.15 & 0.01 & -1.56 & -0.18 & -0.02 \\
\hline & Salinity & 0.65 & 0.03 & 0.23 & 0.59 & 1.43 \\
\hline & Season (spring) & -0.37 & 0.02 & -2.24 & -0.32 & -0.02 \\
\hline & Time (morning) & -0.43 & 0.06 & -1.52 & -0.35 & -0.04 \\
\hline & Time (night) & -0.25 & 0.01 & -1.09 & -0.23 & -0.02 \\
\hline
\end{tabular}

Second, a 50 -fold cross-validation based on a random half of the data set was performed to build the model, and the remaining data were used to test the prediction (Fielding and Bell, 1997).

For both of these approaches, 3 statistics were calculated: Pearson's $r$, root mean square error (RMSE), and the average error (avg. error). Pearson's $r$ measures the linear dependence between predicted and observed values. It can vary from -1 to 1 , with 1 representing a perfect positive correlation between the 2 data sets. The RMSE represents the standard error of the differences between predicted values and observed values, and the avg. error represents the mean error between observed and predicted values. The closer these 2 statistics are to zero, the better the prediction (Potts and Elith, 2006).

\section{Results}

\section{Initial results}

During 1820 trawl hauls, 2372 adult spiny dogfish were caught, of which 2252 were females and 120 males. Seasonally, 2085 females were caught in spring and 167 females were captured in fall, and 64 and 56 males were caught in spring and in fall, respectively.

The final model with the best fit (based on the lowest DIC and LCPO) for CPUE for each sex includes as relevant covariates bathymetry, SST, salinity, chl- $a$ con- centration, season and time of the survey, and the random spatial effect for both sexes (Table 2). Slope of the seabed and distance from the coast were not relevant variables for the model of CPUE of spiny dogfish for both sexes. No relevant interannual differences were found in CPUE variability for both the females and males in the sampling area because all models with the yearly temporal effect resulted in higher DIC than those DIC from models without it.

\section{Females}

Results for adult females indicated that CPUE had a negative relationship with bathymetry (posterior mean: -1.14 ; CrI: -2.52 to -0.22 ), and salinity (posterior mean: -0.94 ; CrI: -1.65 to -0.11 ); therefore, higher values for CPUE of females were predicted to be found in shallow, less saline waters compared with CPUE levels predicted for other depths and more saline waters. Conversely, values of SST (posterior mean: 0.35; CrI: 0.08 to 1.98 ) and chl- $a$ concentration (posterior mean: 0.25; CrI: 0.04 to 1.05 ) indicated a positive relationship with the expected CPUE, indicating that higher CPUE should be expected in warmer waters with higher primary productivity (i.e., higher concentrations of chl-a).

Additionally, there was a seasonal effect for the estimated probability of CPUE of adult females; the highest estimated value occurred in spring (posterior mean: 1.45; CrI: 0.34 to 2.06) compared with the reference level (fall season). 

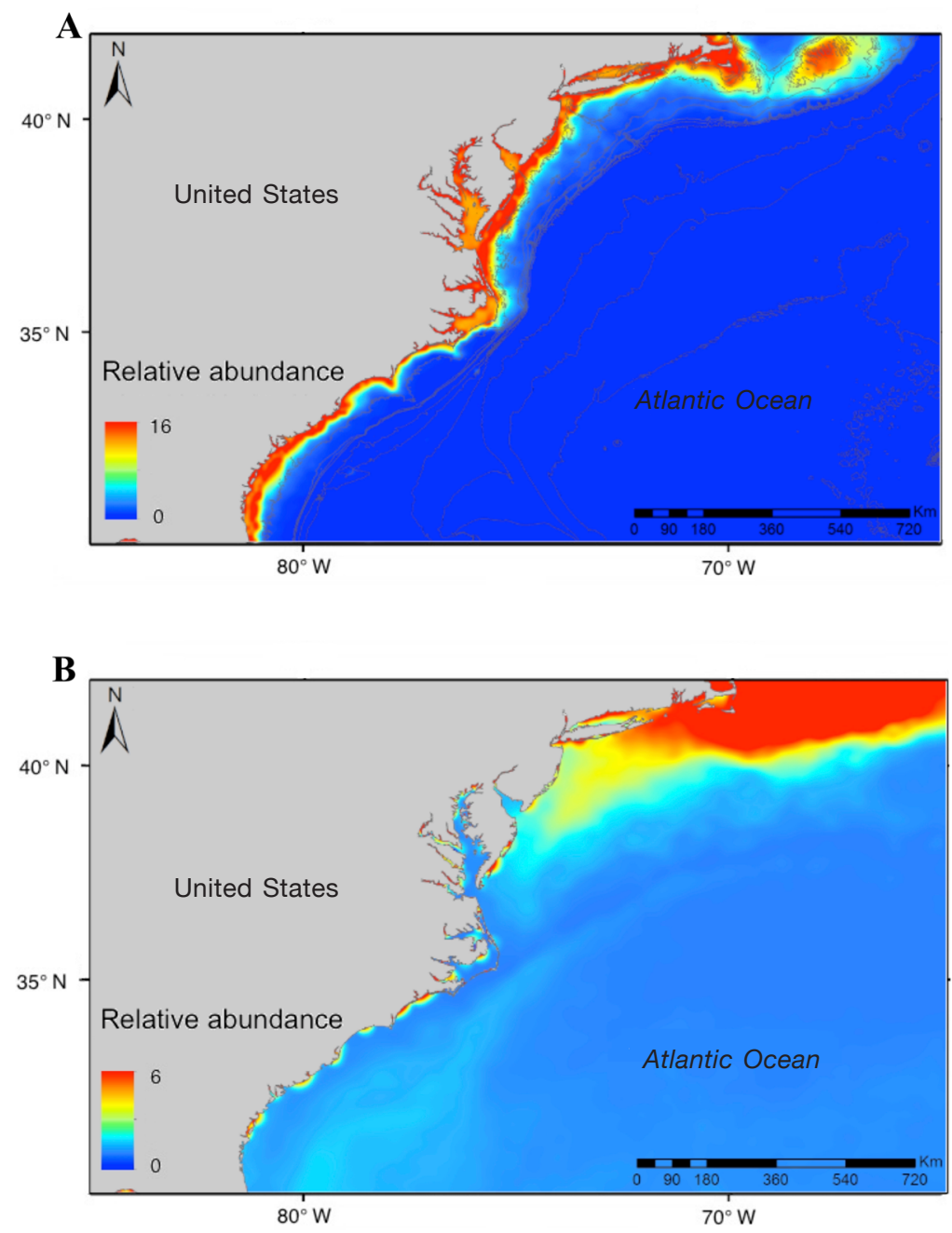

Figure 2

Map of the median of the posterior estimates of the probability of the catch per unit of effort of the mature (A) female and (B) male spiny dogfish (Squalus acanthias) caught during fishery-independent surveys conducted between New England and North Carolina in 20072013. Values of CPUE, which ranged from 16 to 0 for females and from 6 to 0 for males, were used as a proxy for relative abundance.

Morning was the period of the day during a survey with the highest estimated probability of CPUE of adult females (posterior mean: 0.88; CrI: 0.32 to 1.43) with respect to the reference level (afternoon). Conversely, hauls conducted at night had the lowest estimated CPUE (posterior mean: -0.65 ; CrI: -1.24 to $-0.12)$.

Finally, higher estimated values of CPUE for adult females were found for waters off the southern area of the Cape Cod peninsula and off Georges Bank than for CPUE estimates for other areas sampled (Fig. 2A).

\section{Males}

For adult males, a positive relationship between bathymetry and CPUE (posterior mean: 1.85 ; CrI: 1.44 to
2.36) was observed, as well as for salinity and CPUE (posterior mean: 0.65; CrI: 0.23 to 1.43). Predicted values from the model indicated a negative relationship for adult males between expected CPUE and SST (posterior mean: -1.02 ; CrI: -2.33 to -1.51 ) and between expected CPUE and chl- $a$ concentration (posterior mean: -0.15 ; CrI: -1.56 to -0.02 ). We interpret this result as indicating a higher probability of catching adult males as depth and salinity increase and water temperature and chl- $a$ concentration decrease.

The estimated probability of CPUE for adult males indicated a seasonal effect, with lower values in spring (posterior mean: -0.37 ; CrI: -2.24 to -0.02 ) than in fall, the season of the reference level.

Surveys conducted in the morning had the lowest estimated CPUE of adult males (posterior mean: -0.43 ; 
CrI: -1.52 to -0.04$)$ compared with surveys conducted in the afternoon (the reference level), which was the period of time with the highest CPUE. Night-time surveys also had lower values of CPUE (posterior mean = -0.25 ; CrI: -1.09 to -0.02 ) compared with the values from afternoon surveys.

Higher estimated values of CPUE for adult males occurred at higher latitudes, above $40^{\circ} \mathrm{N}$, and off Georges Bank, than estimated values of CPUE from other sampled areas (Fig. 2B).

\section{Model performance}

For model validation, reasonably high values for Pearson's $r$ were obtained for both sexes. In particular, from the model for adult females, an $r$ value of $\sim 0.65$ was obtained in the cross-validation with the original data set, and an $r$ value of $\sim 0.71$ was obtained in the crossvalidation with half of the data set. For adult males, the $r$ value was $\sim 0.68$ in the cross-validation with the original data set and was $\sim 0.74$ in the cross-validation with half of the data set.

Low values of RMSE and avg. error were achieved for adult females, with an RMSE of 0.98 and an avg. error of 0.045 in the cross-validation with the original data set and with an RMSE of 1.14 and an avg. error of -0.023 in the cross-validation with half of the data set (Table 3). For adult males, low values were also observed, with an RMSE of 1.15 and an avg. error of 0.032 in cross-validation with the original data set and an RMSE of 1.11 and an avg. error of -0.018 in the cross-validation with half of the data set (Table 3 ). These validation results indicate a good performance of the 2 models.

\section{Discussion}

This study provides predictive information on the habitat distribution of spiny dogfish in U.S. Atlantic coastal waters, by modeling the CPUE in the NEAMAP survey as a proxy for the abundance of this species. The results of this study offer insight into the key environmental and temporal variables that influence the habitat selection for each of the sexes of this species. For our modeling approach, we assumed CPUE is a proxy for species abundance and that CPUE should be the same for both female and male spiny dogfish, although CPUE is not always a viable proxy for species abundance and is not always the same for each sex because of inherent variability in the catchability coefficient (see Hilborn and Walters, 1992; Walters, 2003; Maunder and Punt, 2004; Maunder et al., 2006). However, the lack of linearity between CPUE and fish abundance is largely reduced when data from standardized fishery-independent surveys are used (Maunder and Punt, 2004), as was done in our study.

Another confounding issue in our analysis was that in the NEAMAP survey, female spiny dogfish markedly outnumbered males, by a ratio of $20: 1$. Ideally, the

\section{Table 3}

Statistics used in the hierarchical Bayesian spatiotemporal model to estimate abundance of spiny dogfish (Squalus acanthias), by sex. The statistics include root mean square error (RMSE) with the original data set, average error (avg. error) with the original data set, root mean square error (RMSE-cross) with half of the data set, and average error (avg. error-cross) with half of the data set.

\begin{tabular}{lcccc}
\hline Sex & RMSE & avg. error & $\begin{array}{c}\text { RMSE- } \\
\text { cross }\end{array}$ & $\begin{array}{c}\text { avg. error } \\
\text {-cross }\end{array}$ \\
\hline Females & 0.98 & 0.045 & 1.14 & -0.023 \\
Males & 1.15 & 0.032 & 1.11 & -0.018 \\
& & & & \\
\hline
\end{tabular}

analysis of data from a simultaneous offshore survey would have been more suitable for determining whether patterns inshore and offshore are the same, but such data were not available. This lack of information points to a need for concurrent offshore sampling to support the extrapolation of our conclusions to the offshore component of and for the generalization of our predictions for the entire U.S. Atlantic stock of spiny dogfish.

Our results related to sex-based segregation and distribution are in line with those reported in other studies. As expected, a higher number of adult females were caught in shallower, inshore, and warmer waters in comparison with adult males, which are more commonly reported in deeper, offshore, and colder waters (Shepherd et al., 2002; Methratta and Link, 2007; Sagarese et al., 2014a).

On the basis of the results of the hierarchical Bayesian spatiotemporal model, abundance of adult female spiny dogfish is predicted to decrease with depth, but abundance of adult males is predicted to increase with depth. In addition, CPUE of adult females is predicted to be higher in warmer, less saline waters and in waters with higher concentrations of chl- $a$, but CPUE of adult males is predicted to be higher in colder, more saline waters, and in waters with lower concentrations of chl- $a$. Nevertheless, adult females occasionally move to deeper waters, mainly in the spring. More studies are needed to understand the drivers for these movements into deeper waters. However, considering that parturition in spiny dogfish is likely to occur in offshore, deeper areas off the edge of the continental shelf and in deep basins (Jensen, 1966; Nammack et al., 1985; Hanchet, 1988; Campana et al., 2009) and that the time of parturition is commonly reported to be between November and January in the northwest Atlantic population (Nammack et al., 1985), despite the observation in a recent study of neonate in more inshore waters off Rhode Island in February (Sulikowski et al., 2013), it is likely that these offshore movements of adult females in the spring are not related to parturition events but might be the result of a strategy to avoid males and 
energy-demanding copulation (Pratt and Carrier, 2001; Sims et al., 2001; Dell'Apa et al., 2014, 2015). More studies are needed to test this hypothesis.

That the CPUE predicted in our analysis for adult females was higher in warmer waters than in less warm waters is in accordance with results of Sagarese et al. (2014a), a study in which adult females in the northeastern U.S. continental shelf large marine ecosystem were observed to occupy significantly warmer waters than those occupied by adult males. In regard to adult male abundance, the results of the Bayesian model obtained from our study are also in agreement with results from Sagarese et al. (2014a): results from both studies indicate a higher occurrence of adult males than adult females in deeper, colder waters. In spiny dogfish, gestation lasts for almost 2 years, and it has been hypothesized that this species may have an evolutionary advantage in that adult, pregnant females actively seek inshore, warmer waters because such habitats can maximize the growth rates of embryos (Sagarese et al., 2014a).

Salinity was found to be a relevant environmental variable for predicting the habitat distribution of spiny dogfish for both sexes-a finding that is in agreement with Shepard et al. (2002) and Sagarese et al. (2014a), but we interpret this result and the results of other studies as a possible artifact of the association of salinity with other key environmental habitat characteristics, such as depth and temperature, that better define habitat selection of spiny dogfish. Generally, inshore waters are less saline than offshore environments because of the increased contribution of freshwater runoff.

On the basis of the Bayesian model, we predict that abundance of adult females should be higher in the spring than in the fall and higher in the morning than in the afternoon and night. Conversely, abundance of adult males is predicted to be higher in the fall than in the spring, as well as higher in the afternoon than at other times of day. For adult females, this predicted seasonal pattern of abundance is in agreement with results from the NEFSC survey, which is conducted farther offshore than the NEAMAP survey (Sagarese et al., 2014b). This pattern also indicates that the habitat distribution of adult females in the spring is mainly driven by environmental factors (i.e., temperature and depth) and that habitat distribution in the fall is mainly influenced by ecological factors (i.e., prey abundance) (Sagarese et al., 2014a, 2014b).

For adult males, the results of this study contrast with those reported by Sagarese et al. (2014b), in that we predicted a greater abundance of males in the fall than in the spring. We acknowledge that our analysis is based on fewer males than females, but we are confident that the level of uncertainty that may result from this limited number is included within the parameters analyzed by a Bayesian approach. In combination, however, our results and those of Sagarese et al. (2014b), for inshore and offshore waters, respectively, indicate that abundance of adult males should be higher in the fall than in the spring in inshore coastal waters, al- though a greater chance for catching larger aggregations of adult males may occur in offshore, deeper waters in the spring. More studies are needed to support this hypothesis and to analyze specific seasonal differences in habitat distribution and abundance of spiny dogfish, by sex, throughout its range. Unfortunately, it was not possible to run the hierarchical Bayesian spatiotemporal model and develop probability distribution maps for each sex, by season, as with the maps obtained for CPUE for each sex, because of the consistent presence in the survey of locations that were sampled multiple times.

This study is the first one to provide a predictive model for the spatial distribution of each sex of spiny dogfish on the basis of time of day, which previously has been suggested to be an important aspect associated with the sexual segregation of this species (Dell'Apa et al., 2014). Such information could be used to enhance fishery sustainability by developing fishery strategies based on the distribution and habitat association of each of the sexes. For example, targeting adult females inshore, in shallower waters, would result in greater pressure on the entire U.S. Atlantic stock of spiny dogfish. Fishery sustainability is measured in terms of fishing mortality and spawning stock biomass, and adult female biomass is used as a biological reference point. Although the spiny dogfish is not currently considered overfished and overfishing is not occurring, low numbers of adult females are expected to be recruiting to the stock over the next few years (Rago and Sosebee ${ }^{4}$; Dell'Apa et al., 2015).

Considering the concentration of chl- $a$ as a valid proxy for primary production (de Leiva Moreno et al., 2000), adult females were predicted to associate with habitats characterized by higher productivity, but adult males were predicted to occur in less productive waters. As with our analysis of results for salinity, we interpreted this result for chl- $a$ concentration as the direct association of primary productivity with the preferred habitat for females rather than as a driver per se. Because adult females are found most commonly inshore, in shallower and warmer waters where primary production is usually highest, it is likely that chl-a concentration and primary production should not be considered as an important predictive variable for abundance of spiny dogfish. However, for coastal elasmobranch species, such as the Atlantic sharpnose shark (Rhizoprionodon terraenovae), chl-a concentration has been found to be an important environmental variable that affects the abundance and habitat association of that species (Drymon et al., 2013). Papastamatiou et al. (2013) reported that for both sexes of tiger shark (Galeocerdo cuvier), immigration across the Hawaiian Archipelago was correlated with chl- $a$ concentration-a result that they interpreted to be indicative of a foraging activity. It is, therefore, likely that for large pelagic shark species, such as the blue shark (Prionace glauca), primary production is an important variable that influences species habitat distribution (Mitchell et al., 2014). 
Our results indicate that adult female spiny dogfish may select warmer inshore habitats not for foraging but to reduce gestation time of embryos, as has been reported to occur in the round stingray (Urobatis halleri) and may be common in other elasmobranchs (Jirik and Lowe, 2012). Further research should be focused on understanding the influence of primary productivity on habitat selection in spiny dogfish, by sex, to evaluate the link with gestation and the possible link with foraging success (Dell'Apa et al., 2015).

From a management perspective, the results of this study indicate a higher probability of catching spiny dogfish at higher latitudes, mainly on the Georges Bank shelf area, where the stock of this species is commonly reported to aggregate between spring and fall (Rulifson, 2010). Results also indicate that there is a higher probability of adult male aggregations inshore in coastal waters during the fall. Additionally, a lower abundance of adult females was predicted to be found in the fall in these same waters. Combined, these results indicate that the Georges Bank shelf area may be explored for the development of a male-only directed fishery in the fall. However, further studies are needed to confirm this hypothesis, studies that possibly could combine data analyses of both fishery-independent (e.g., NEFSC surveys) and fishery-dependent surveys in the New England region.

Additionally, the results from this study indicate that a potential male-only directed fishery, mainly in the Georges Bank shelf area, could be limited to fishing in the afternoon, when fewer aggregations of adult females are predicted to be associated with coastal waters, and in the fall, when higher numbers of adult females are predicted to select deeper waters. Sagarese et al. (2014a) noted that during the fall, adult females may move into offshore waters as a strategy to avoid encountering adult males-a suggestion also made by other authors (Verissimo et al., 2011; Dell'Apa et al., 2014). Future research should be undertaken to compare and integrate the spatiotemporal habitat distribution of spiny dogfish, by sex, found in this study with that of fishery-independent surveys, such as the surveys that the NEFSC has conducted in offshore waters and for a longer period of time, and with that of fishery-dependent surveys, which provide less standardized but more direct information on the influence of fishery exploitation of this species between New England and North Carolina. Because temperature and depth are key environmental variables for prediction of the abundance in both sexes, more studies are also needed to understand the influence of climate change in the spatial distribution of spiny dogfish along the northwest Atlantic coast and continental shelf (Nye et al., 2009; Sagarese et al., 2014a).

\section{Acknowledgments}

We thank all the people who have worked on the F/V Darana $R$ at the Virginia Institute of Marine Science in Gloucester Point, Virginia, from crew members to those people who volunteered to help collect data and samples during the surveys. We are grateful to S. Sagarese and to 3 anonymous reviewers for their valuable inputs and comments that helped to improve the quality of this manuscript.

\section{Literature cited}

Austin, M.

2007. Species distribution models and ecological theory: a critical assessment and some possible new approaches. Ecol. Model. 200:1-19. Article

Banerjee, S., B. P. Carlin, and A. E. Gelfand.

2004. Hierarchical modeling and analysis for spatial data, 474 p. Chapman \& Hall/CRC, Boca Raton, FL.

Bubley, W. J., J. A. Sulikowski, D. M. Koester, and P. C. W. Tsang.

2013. Using a multi-parameter approach to reassess maturity of spiny dogfish, Squalus acanthias, following increased fishing pressure in the Western North Atlantic. Fish. Res. 147:202-212. Article

Campana, S. E., D. W. Kulka, and S. Joyce.

2009. Growth and reproduction of spiny dogfish off the eastern coast of Canada, including inferences on stock structure. In Biology and management of dogfish sharks (V. F. Gallucci, G. A. McFarlane, and G. G. Bargmann, eds.), p. 195-208. Am. Fish. Soc., Bethesda, MD.

Colloca, F., V. Bartolino, G. J. Lasinio, L. Maiorano, P. Sartor, and G. Ardizzone.

2009. Identifying fish nurseries using density and persistence measures. Mar. Ecol. Prog. Ser. 381:287-296. Article

Compagno, L., M. Dando, and S. Fowler.

2005. Princeton field guides: sharks of the world, $496 \mathrm{p}$. Princeton Univ. Press, Princeton, NJ.

Conradt, L.

2005. Definitions, hypotheses, models, and measures in the study of animal segregation. In Sexual segregation in vertebrates: ecology of the two sexes (K. E. Ruckstuhl and P. Neuhaus, eds.), p. 11-32. Cambridge Univ. Press, Cambridge, UK.

de Leiva Moreno, J. I., V. N. Agostini, J. F. Caddy, and F. Carocci.

2000. Is the pelagic-demersal ratio from fishery landings a useful proxy for nutrient availability? A preliminary data exploration for the semi-enclosed seas around Europe. ICES J. Mar. Sci. 57:1091-1102. Article

Dell'Apa, A., J. C. Johnson, D. G. Kimmel, R. A. Rulifson.

2013. The international trade and fishery management of spiny dogfish: a social network approach. Ocean Coast. Manage. 80:65-72. Article

Dell'Apa, A., J. Cudney-Burch, D. G. Kimmel, and R. A. Rulifson.

2014. Sexual segregation of spiny dogfish in fishery-dependent surveys in Cape Cod, Massachusetts: potential management benefits. Trans. Am. Fish. Soc. 143:833-844. Article

Dell'Apa, A., C. W. Bangley, and R. A. Rulifson.

2015. Who let the dogfish out? A review of management and socio-economic aspects of spiny dogfish fisheries. Rev. Fish Biol. Fish. 25:273-295. Article

Drymon, J. M., L. Carassou, S. P. Powers, M. Grace, J. Dindo, and B. Dzwonkowski.

2013. Multiscale analysis of factors that affect the distri- 
bution of sharks throughout the northern Gulf of Mexico. Fish. Bull. 111:370-380. Article

Elith, J., and J. R. Leathwick.

2009. Species distribution models: ecological explanation and prediction across space and time. Annu. Rev. Ecol. Evol. Syst. 40:677-697. Article

Espinoza, M., M. Cappo, M. R. Heupel, A. J. Tobin, and C. A. Simpfendorfer.

2014. Quantifying shark distribution patterns and species-habitat associations: implications of marine park zoning. PLoS One 9(9):e106885. Article

Fielding, A. H., and J. F. Bell.

1997. A review of methods for the assessment of prediction errors in conservation presence/absence models. Environ. Conserv. 24:38-49.

Ford, E.

1921. A contribution to our knowledge of the life-histories of the dogfishes landed at Plymouth. J. Mar. Biol. Assoc. U. K. 12:468-505. Article

Gelfand, A. E., J. A. Silander Jr., S. Wu, A. Latimer, P. O. Lewis, A. G. Rebelo, and M. Holder.

2006. Explaining species distribution patterns through hierarchical modeling. Bayesian Anal. 1:41-92. Article

Hanchet, S.

1988. Reproductive biology of Squalus acanthias from the east coast, South Island, New Zealand. N.Z. J. Mar. Freshw. Res. 22:537-549. Article

Hijmans, R. J.

2013. Introduction to the "raster" package (version 2.125). R Foundation for Statistical Computing, Vienna, Austria.

Hilborn, R., and C. J. Walters (eds).

1992. Quantitative fisheries stock assessment: choice, dynamics and uncertainty, 570 p. Chapman \& Hall, New York.

Jensen, A. C.

1966. Life history of the spiny dogfish. Fish. Bull. 65:527-554.

Jirik, K. E., and C. G. Lowe.

2012. An elasmobranch maternity ward: female round stingrays Urobatis halleri use warm, restored estuarine habitat during gestation. J. Fish Biol. 80:1227-1245. Article

Lack, M.

2006. Conservation of spiny dogfish Squalus acanthias: a role for CITES?, 40 p. TRAFFIC International, Cambridge, UK. [Available from website.]

Martins, T. G., D. Simpson, F. Lindgren, and H. Rue. 2013. Bayesian computing with INLA: new features. Comput. Stat. Data Anal. 67:68-83. Article

Maunder, M. N., and A. E. Punt.

2004. Standardizing catch and effort data: a review of recent approaches. Fish. Res. 70:141-159. Article

Maunder, M. N., J. R. Sibert, A. Fonteneau, J. Hampton, P. Kleiber, and S. J. Harley.

2006. Interpreting catch per unit effort data to assess the status of individual stocks and communities. ICES J. Mar. Sci. 63:1373-1385. Article

Methratta, E. T., and J. S. Link.

2007. Ontogenetic variation in habitat association for four groundfish species in the Gulf of Maine-Georges Bank region. Mar. Ecol. Prog. Ser. 338:169-181. Article

Mitchell, J. D., K. J. Collins, P. I. Miller, and L. A. Suberg.

2014. Quantifying the impact of environmental variables upon catch per unit effort of the blue shark Prionace glauca in the western English Channel. J. Fish Biol. 85:657-670. Article

Muñoz, F., M. G. Pennino, D. Conesa, A. López-Quílez, and J. M. Bellido.

2013. Estimation and prediction of the spatial occurrence of fish species using Bayesian latent Gaussian models. Stoch. Environ. Res. Risk Assess. 27:1171-1180. Article

Nammack, M. F., J. A. Musick, and J. A. Colvocoresses.

1985. Life history of spiny dogfish off the northeastern United States. Trans. Am. Fish. Soc. 114:367-376. Article

Nye, J. A., J. S. Link, J. A. Hare, and W. J. Overholtz.

2009. Changing spatial distribution of fish stocks in relation to climate and population size on the Northeast United States continental shelf. Mar. Ecol. Prog. Ser. 393:111129. Article

Overholtz, W. J., and A. V. Tyler.

1985. Long-term responses of the demersal fish assemblages of Georges Bank. Fish. Bull. 83:507-520.

Papastamatiou, Y. P., C. G. Meyer, F. Carvalho, J. J. Dale, M. R. Hutchinson, and K. N. Holland.

2013. Telemetry and random-walk models reveal complex patterns of partial migration in a large marine predator. Ecology 94:2595-2606. Article

Pennino, M. G., F. Muñoz, D. Conesa, A. López-Quílez, and J. M. Bellido.

2014. Bayesian spatio-temporal discard model in a demersal trawl fishery. J. Sea Res. 90:44-53. Article

Perry, R. I., and S. J. Smith.

1994. Identifying habitat associations of marine fishes using survey data: an application to the northwest Atlantic. Can. J. Fish. Aquat. Sci. 51:589-602. Article

Pittman, S. J., and K. A. Brown.

2011. Multi-scale approach for predicting fish species distributions across coral reef seascapes. PLoS One 6(5):e20583. Article

Potts, J. M., and J. Elith.

2006. Comparing species abundance models. Ecol. Model. 199:153-163. Article

Pratt, H. L., Jr., and J. C. Carrier.

2001. A review of elasmobranch reproductive behavior with a case study on the nurse shark, Ginglymostoma cirratum. Environ. Biol. Fish. 60(1):157-188. Article

$\mathrm{R}$ Core Team.

2014. R: a language and environment for statistical computing. R Foundation for Statistical Computing, Vienna, Austria. [Available from website, accessed August 2014.]

Roos, M., and L. Held.

2011. Sensitivity analysis in Bayesian generalized linear mixed models for binary data. Bayesian Anal. 6:259278. [Available from website.]

Roos, N. C., A. R. Carvalho, P. F. Lopes, and M. G. Pennino.

2015. Modeling sensitive parrotfish (Labridae: Scarini) habitats along the Brazilian coast. Mar. Environ. Res. 110:92-100. Article

Ruckstuhl, K. E., and T. H. Clutton-Brock

2005. Sexual segregation and the ecology of the two sexes. In Sexual segregation in vertebrates: ecology of the two sexes (K. E.Ruckstuhl and P. Neuhaus, eds.), p. 3-10. Cambridge Univ. Press, Cambridge, UK. Article

Rue, H., S. Martino, and N. Chopin.

2009. Approximate Bayesian inference for latent Gauss- 
ian models by using integrated nested Laplace approximations. J. R. Stat. Soc., B 71:319-392. Article

Rulifson, R. A.

2010. Tagging spiny dogfish overwintering in North Carolina, and summering in Bay of Fundy, Canada. In Proceedings of the Transboundary Resources Assessment Committee (TRAC) spiny dogfish review; Woods Hole, MA, 30 March-2 April 2009, p. 15-19. [Available from website.]

Sagarese, S. R., M. G. Frisk, T. J. Miller, K. A. Sosebee, J. A. Musick, and P. J. Rago.

2014a. Influence of environmental, spatial, and ontogenetic variables on habitat selection and management of spiny dogfish in the Northeast (US) shelf large marine ecosystem. Can. J. Fish. Aquat. Sci. 71:567-580. Article

Sagarese, S. R., M. G. Frisk, R. M. Cerrato, K. A. Sosebee, J. A. Musick, and P. J. Rago.

2014b. Application of generalized additive models to examine ontogenetic and seasonal distributions of spiny dogfish (Squalus acanthias) in the Northeast (US) shelf large marine ecosystem. Can. J. Fish. Aquat. Sci. 71:847-877. Article

Shepherd, T., F. Page, and B. Macdonald.

2002. Length and sex-specific associations between spiny dogfish (Squalus acanthias) and hydrographic variables in the Bay of Fundy and Scotian Shelf. Fish. Oceanogr. 11:78-89. Article

Sims, D. W.

2005. Differences in habitat selection and reproductive strategies of male and female sharks. In Sexual segregation in vertebrates: ecology of the two sexes (K. E. Ruckstuhl and P. Neuhaus, eds.), p. 127-147. Cambridge Univ. Press, Cambridge, UK. Article

Sims, D. W., J. P. Nash, and D. Morritt.

2001 Movements and activity of male and female dogfish in a tidal sea lough: alternative behavioural strategies and apparent sexual segregation. Mar. Biol. 139:1165-1175. Article

Sosebee, K. A.

2005. Are density-dependent effects on elasmobranch maturity possible? J. Northwest Atl. Fish. Sci. 35:115-124. Article

Spiegelhalter, D. J., N. G. Best, B. P. Carlin, and A. van der Linde.

2002. Bayesian measures of model complexity and fit. J. R. Stat. Soc., B. 64:583-639. Article

Springer, S.

1967. Social organization of shark populations. In Sharks, skates, and rays (P. W. Gilbert, R. F. Mathewson, and D. P. Rall, eds.), p. 149-174. The Johns Hopkins Press, Baltimore, MD.

Sulikowski, J. A., B. K. Prohaska, A. E. Carlson, A. M. Cicia, C. T. Brown, and A. C. Morgan.

2013. Observations of neonate spiny dogfish, Squalus acanthias, in Southern New England: a first account of a potential pupping ground in the Northwestern Atlantic. Fish. Res. 137: 59-62. Article

Veríssimo, A., D. Grubbs, J. McDowell, J. Musick, and D. Portnoy.

2011. Frequency of multiple paternity in the spiny dogfish Squalus acanthias in the Western North Atlantic. J. Hered. 102:88-93. Article

Walters, C.

2003. Folly and fantasy in the analysis of spatial catch rate data. Can. J. Fish. Aquat. Sci. 60:1433-1436. Article

Wearmouth, V. J., and D. W. Sims.

2008. Sexual segregation in marine fish, reptiles, birds and mammals: behaviour patterns, mechanisms and conservation implications. Adv. Mar. Biol. 54:107-170. Article 